\title{
Cambio climático y enfermedades infecciosas. Un nuevo escenario epidemiológico
}

\author{
Jaime Cerda L., Gonzalo Valdivia C., M. Teresa Valenzuela B. y Jairo Venegas L.
}

\section{Climate change and infectious diseases. A novel epidemiological scenario}

For the international scientific community, it is undoubted that planetary temperature is increasing, being projected an average raise of $1.0^{\circ} \mathrm{C}-3.5^{\circ} \mathrm{C}$ by the year 2100 . Forecasted consequences are diverse, most of them adverse for human health, including the establishment of favorable epidemiological scenarios for the emergence and reemergence of infectious diseases. The present article summarizes the available evidence regarding the mechanisms that promote climate change, its environmental effects and its consequences on human health. In order to accomplish this objective, demonstrated changes in the dynamics of zoonotic, vectorial, food and water-borne diseases are described. The position of Chile in the international community is commented, as well as multiple pending challenges, among which outstands the importance of incorporating professionals that work in the health sector to the national debate.

Key words: Climate change, global warming, infectious diseases.

Palabras clave: Cambio climático, calentamiento global, enfermedades infecciosas.
Pontificia Universidad Católica de Chile

Facultad de Medicina Departamento de Salud Pública (GVC) Programa de Especialidad en Salud Pública (JCL)

Universidad de los Andes Facultad de Medicina Departamento de Salud Pública y

Epidemiología (MTVB)

Universidad de Chile Facultad de Medicina Escuela de Salud Pública Programa de Doctorado en Salud Pública (JVL)

Artículo por invitación Recibido: 18 agosto 2008

Correspondencia a: Jaime Cerda Lorca jcerda@med.puc.cl

\section{Introducción}

$\mathbf{P}$ ara la comunidad científica mundial, el aumento progresivo de la temperatura del clima planetario es un hecho inequívoco. Once de los 12 años que integran el período 1995-2006 se encuentran entre los más cálidos desde 1850, según los registros instrumentales de temperatura global en superficie. Numerosas investigaciones han documentado las consecuencias de este proceso, reflejado en un acelerado derretimiento de masas de nieve y su consiguiente aumento del nivel promedio de los $\operatorname{mares}^{1}$ (Figura 1). Siendo el clima un componente importante de numerosos ecosistemas, cualquier variación mayor que éste experimente afectará a los demás componentes, entre los cuales se incluyen microorganismos, vectores insectarios, reservorios animales y seres humanos susceptibles, generando un cambio en la incidencia y distribución de numerosas patologías, mayoritariamente infecciosas. Al respecto, existe preocupación mundial en torno al impacto que el cambio climático puede producir sobre la distribución y carga de enfermedad, especialmente en países en vías de desarrollo ${ }^{2}$.

El Panel Intergubernamental sobre Cambio Climático $^{1}$, principal colaboración científica internacional en la materia, ha proyectado un aumento de la temperatura promedio planetaria de $1,0{ }^{\circ} \mathrm{C}-3,5^{\circ} \mathrm{C}$ para el año 2100 , con variaciones regionales considerables. Las consecuencias pronosticadas son muy diversas, siendo en su mayoría adversas para la salud humana ${ }^{3}$, entre las cuales se incluyen el establecimiento de escenarios epidemiológicos propicios para la emergencia y reemergencia de enfermedades infecciosas en diversas regiones del planeta ${ }^{4,5}$. Tanto su novedad como sus potenciales efectos deletéreos imponen la necesidad de caracterizarles con prontitud, con el fin de establecer oportunamente estrategias de prevención, mitigación y adaptación destinadas a reducir su impacto medioambiental. Frente a tal amenaza, surgen de inmediato una serie de preguntas: ¿Cuál es la evidencia disponible en torno a los mecanismos generadores del cambio climático? ¿Qué efectos medioambientales le son atribuibles? ¿Cuáles son sus consecuencias sobre la salud humana? El presente artículo intentará dar respuesta a estas y otras interrogantes sintetizando la evidencia disponible en torno a los mecanismos generadores del cambio climático, sus efectos medioambientales y sus consecuencias sobre la salud humana, con especial énfasis en los cambios previstos en la dinámica de ocurrencia de enfermedades infecciosas. 


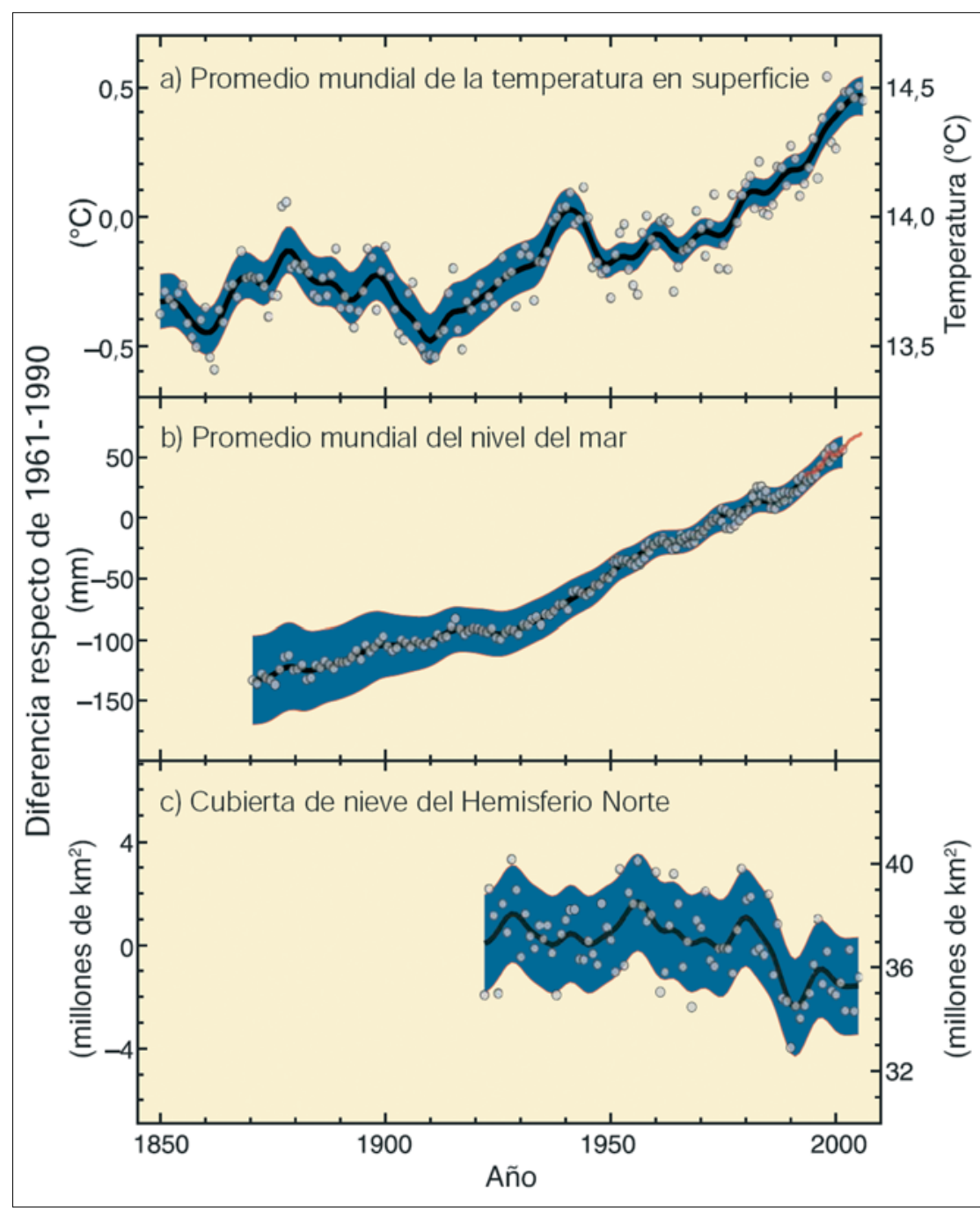

Figura 1. Cambios en la temperatura, en el nivel del mar y en la cubierta de nieve del hemisferio norte. Variación observada de: a) el promedio mundial de las temperaturas en superficie; b) el promedio mundial del nivel del mar a partir de datos mareométricos (azul) y satelitales (rojo); y c) la cubierta de nieve del Hemisferio Norte durante marzo-abril. Todas las diferencias han sido calculadas respecto de los promedios correspondientes durante el período 1961-1990. Las curvas alisadas representan los valores promediados decenalmente, mientras que los círculos denotan los valores anuales. Las áreas sombreadas representan los intervalos de incertidumbre estimados a partir de un análisis completo de las incertidumbres conocidas (a y b) y de la serie temporal c). Fuente: Grupo Intergubernamental de Expertos sobre el Cambio Climático. Cambio climático 2007: Informe de Síntesis. Resumen para Responsables de Políticas (figura R.R.P. 1.). Disponible en http://www.ipcc.ch. Reproducido con autorización de los autores.

\section{¿Qué factores explican el fenómeno del cambio climático? ¿Cómo se vincula este fenómeno y sus efectos sobre la salud humana?}

La evidencia disponible señala que más de $90 \%$ del cambio climático planetario es atribuible a actividades humanas ${ }^{6,7}$, responsables de una intensificación del "efecto invernadero". En términos simples, parte de los rayos solares que alcanzan la superficie terrestre son nuevamente irradiados hacia el espacio en forma de rayos infrarrojos, reteniéndose una fracción por acción de los gases que componen la atmósfera terrestre, cubierta que actúa de modo análogo a un invernadero planetario. Durante miles de años el efecto invernadero ha propiciado las condiciones necesarias para la génesis y mantenimiento de diversas formas de vida; en su ausencia, la tierra sería un planeta estéril, cuya temperatura promedio alcanzaría los $-18^{\circ} \mathrm{C}^{3,7}$. Las concentraciones atmosféricas de los llamados "gases de efecto invernadero" (dióxido de carbono, metano y óxido nitroso) han aumentado marcadamente a partir de 1750, excediendo hoy en día ampliamente sus valores anteriores a la Revolución Industrial. La quema de combustibles fósiles (e.g. carbón, petróleo y gas) unida a una progresiva deforestación, ha tenido como consecuencia una elevación de la concentración atmosférica de dióxido de carbono y metano a niveles muy superiores al rango de valores normales establecido para los últimos 650.000 años. Esta situación ha sido responsable de la tendencia lineal de calentamiento objetivada durante los últimos 100 años, proyectándose mediante modelos matemáticos un aumento sostenido de la temperatura planetaria durante el presente siglo, cuya magnitud será dependiente de escenarios específicos de emisiones ${ }^{1}$.

La secuencia cambio climático-efectos sobre la salud humana no puede ser comprendida sin referirse a un conjunto de variables intermediarias entre ambos eventos, siendo éstas consecuencias del cambio climático y, a su vez, causas (no necesarias ni suficientes) de efectos sobre la salud humana. Entre estas variables intermediarias destacan el aumento de la frecuencia e intensidad de eventos climáticos extremos (e.g. olas de calor, inundaciones, sequías), efectos en el rango y actividad de vectores y parásitos, cambios ecológicos locales de agentes infecciosos transmitidos por agua y alimentos, disminución de la productividad agrícola y aumento del nivel oceánico (Tabla 1$)^{3}$. La interacción de estas variables en un determinado tiempo y lugar tiene como consecuencia el establecimiento de escenarios epidemiológicos propicios para la emergencia y reemergencia de enfermedades infecciosas, muchas de ellas consideradas erradicadas. A continuación, se describirán los cambios observados y proyectados en dos tipos de enfermedades infecciosas "vectoriales" y "zoonóticas y transmitidas por agua y alimentos", posiblemente las más afectadas por el cambio climático.

\section{Cambios en la dinámica de enfermedades} zoonóticas y vectoriales. Un claro ejemplo de la asociación entre cambio climático y enfermedades infecciosas

La emergencia y reemergencia de enfermedades vectoriales y zoonóticas en numerosas regiones del 
Variables intermediarias

- Cambios en la frecuencia e intensidad de eventos climáticos extremos

\section{Consecuencias en salud}

- Muertes, traumatismos, trastornos psicológicos, daño a la infraestructura de salud pública

- Cambios en rangos geográficos e incidencia de enfermedades vectoriales

- Cambios en la incidencia de diarrea y otras enfermedades infecciosas

- Cambios ecológicos locales de agentes infecciosos transmitidos por agua y alimentos

- Cambios en la productividad de alimentos mediados por cambios climáticos y sus pestes y enfermedades asociadas

- Desnutrición y hambrunas y sus consiguientes trastornos inmunitarios y en el crecimiento y desarrollo infantil

- Aumento del nivel oceánico, con desplazamientos de poblaciones y daños sobre infraestructura

- Impacto biológico de cambios en la contaminación del aire (incluyendo pólenes y esporas)

- Trastornos sociales, económicos y demográficos mediados por efectos sobre la economía, infraestructura y disponibilidad de recursos

- Reducción de terrenos cultivables, aumento del riesgo de enfermedades infecciosas y trastornos psicológicos

- Asma y alergias, otros trastornos respiratorios agudos y crónicos y muertes

- Amplio rango de consecuencias en salud pública: trastornos nutricionales y psicológicos, enfermedades infecciosas y conflictos civiles

Modificado de Haines $A$, et al. $^{3}$

planeta constituye un claro ejemplo de asociación entre cambio climático y efectos sobre la salud humana. Diversas variables intermediarias dan cuenta de esta asociación (Tabla 1), teniendo como consecuencia final un cambio en el comportamiento epidemiológico de numerosas patologías tales como malaria, dengue, fiebre chikungunya y enfermedad de Lyme, las cuales emergen y reemergen en áreas donde hasta hace poco tiempo se consideraban erradicadas.

Un caso emblemático lo constituye la malaria, patología responsable de 350-500 millones de casos por año y más de un millón de muertes. A medida que las temperaturas globales aumentan y se alteran los patrones de lluvias, el mosquito anófeles expande su hábitat hacia mayores latitudes y altitudes consideradas áreas libres de malaria, encontrando en dichas zonas un alto número de personas susceptibles ${ }^{7}$. Por otro lado, el período de tiempo que tarda el Plasmodium en desarrollarse al interior del anófeles disminuye a medida que aumenta la temperatura ambiental, hecho que podría favorecer una mayor transmisibilidad de esta enfermedad conforme aumenta el clima planetario. Naturalmente, el cambio climático no es la única variable que explica el resurgimiento de la malaria en diversas áreas del planeta, postulándose una serie de factores explicatorios complementarios tales como el incremento de la resistencia a antimaláricos, cesación de medidas de control vectoriales, deforestación y migraciones humanas 5 . Este último factor reviste particular importancia (especialmente en un mundo globalizado), por cuanto los desplazamientos de individuos y familias entre diferentes países aumentan tanto el número de personas susceptibles de enfermar como la proba- bilidad de que mosquitos no infectados adquieran el parásito, en caso de encontrarse la población migrante contagiada.

Tanto más emblemático es el caso del dengue, patología que hoy en día afecta entre 50 y 100 millones de personas anualmente. Su vector principal, el Aedes aegypti (mosquito que también es vector del virus de la fiebre amarilla) presenta hoy en día una distribución mundial en los trópicos. $\mathrm{Su}$ creciente expansión no solamente ha ocurrido a consecuencia de la existencia de climas progresivamente más cálidos y húmedos, sino también promovida por una creciente urbanización no planificada, especialmente en países en vías de desarrollo, cuyas ciudades ofrecen hábitats idóneos para el desarrollo de las larvas del mosquito (e.g. restos de agua en envases plásticos y neumáticos en desuso $)^{5}$. Tal es la situación de América Latina, región que cuenta con $77 \%$ de población urbana (2005) y donde un número considerable de personas viven en comunidades altamente urbanizadas, con redes sanitarias deficientes y medidas de control vectoriales insuficientes. Tan alta concentración de personas conviviendo en espacios geográficos relativamente pequeños aumenta la masa crítica de transmisibilidad del dengue ${ }^{8}$.

La evidencia ha demostrado que la incidencia de dengue en áreas endémicas presenta estacionalidad y periodicidad inter-anual, reflejo de cambios en las condiciones de temperatura y humedad. Asimismo, la incidencia de dengue ha sido correlacionada positivamente a los fenómenos climáticos de El Niño/La Niña, cuya frecuencia se ha visto incrementada a partir de la década de 1970 en comparación a los últimos 100 años9. 
Al igual que en el caso de la malaria, el cambio climático operaría como un catalizador de un proceso multifactorial, cuya consecuencia final es un cambio en la epidemiología de dos importantes enfermedades vectoriales.

El nuevo escenario climático planetario no solamente tiene consecuencias sobre países en vía de desarrollo, sino también en naciones del primer mundo. A partir de 1996 se han registrado epidemias de virus Nilo Oeste (West Nile) con un número sin precedentes de muertes y casos graves de encefalitis en Rumania, Rusia y E.U.A. (específicamente Nueva York). Desde 1999, el virus se ha expandido en dirección oeste sobre gran parte del continente norteamericano, encontrándose en más de 110 especies de aves salvajes y domésticas, siendo muchas de ellas reservorios competentes $^{5}$. Por su parte, durante 2007 se reportó el primer brote de fiebre chikungunya (enfermedad viral transmitida por el mosquito Aedes albopictus) en un área no-tropical, específicamente en Italia, identificándose entre los meses de julio y septiembre 205 casos. El análisis filogenético del virus chikungunya demostró una alta similitud entre las cepas encontradas en Italia con aquellas identificadas en un brote ocurrido previamente en islas del Océano Índico ${ }^{10}$, reflejo de un intenso proceso de migración vectorial. Por último, entre los meses de enero y marzo de 2008 se documentó la ocurrencia de un brote epidémico de fiebre amarilla en zonas urbanas aledañas a la ciudad de Asunción, Paraguay, confirmándose 24 casos y 8 muertes. En aquel país no se había registrado un brote a causa de esta enfermedad en los últimos 34 años, situación que motivó la implementación de una campaña de vacunación masiva (1,5 millones de personas), con el fin de proteger a la población susceptible en áreas consideradas de riesgo ${ }^{11}$.

\section{Cambios en la dinámica de enfermedades transmitidas por agua y alimentos. Una segunda modalidad de asociación entre cambio climático y enfermedades infecciosas}

En el planeta, se estima que 1.100 millones de personas carecen de suministro de agua potable y 2.400 millones de personas carecen de saneamiento básico ${ }^{4}$. Una de las consecuencias del cambio climático sobre los sistemas hidrológicos es la reducción de la disponibilidad de agua y el aumento de sequías en diversas regiones del planeta, esperándose un incremento del número de personas afectadas por las carencias anteriormente señaladas ${ }^{1}$. El escenario se torna más riesgoso si se considera que las lluvias intensas e inundaciones facilitan el transporte veloz de patógenos hacia las fuentes de suministro de agua ${ }^{2}$.

La sobrevida y persistencia de microorganismos causantes de enfermedad está directamente influenciada por la temperatura. Se ha demostrado que los principales microorganismos causantes de gastroenteritis aguda se multiplican más rápidamente en condiciones más cálidas, tal cual indica la asociación directa observada entre el número de casos mensuales de salmonelosis en Nueva Zelandia y la temperatura media mensual ${ }^{12}$. Por consiguiente, es esperable un aumento en la frecuencia de brotes y epidemias de enfermedades como cólera y fiebre tifoidea si la calidad del agua sufre un deterioro. Este hecho reviste vital importancia si se considera que, según estimaciones de la Organización Mundial de la Salud (OMS), aproximadamente 1,62 millones de niños bajo 5 años de edad mueren anualmente por diarrea, siendo la mayoría de los casos atribuible a aguas contaminadas ${ }^{7}$. El aumento en el número de episodios de diarrea impone también una alta carga sanitaria a los sistemas de salud. $\mathrm{Al}$ respecto, Checkley y colaboradores, analizaron los efectos del fenómeno de El Niño en la epidemiología de las diarreas infantiles en Lima, Perú ${ }^{13}$. Durante la ocurrencia de este fenómeno climático (1997-98), la temperatura ambiental promedio aumentó $5^{\circ} \mathrm{C}$, registrándose un incremento de $200 \%$ en la tasa de ingresos diarios a una Unidad de Rehidratación Oral. Los investigadores determinaron que 6.225 ingresos $(10,9 \%$ del total) fueron atribuibles a $\mathrm{El}$ Niño, con un costo aproximado de US\$277.000. En base a datos registrados con anterioridad a la presencia de este fenómeno climático, la investigación demostró un aumento de $8 \%$ en la tasa de ingresos por cada grado de aumento de la temperatura promedio ambiental. Los resultados de esta investigación concuerdan con los reportados por Gil y cols, quienes demostraron una correlación positiva y significativa entre la incidencia de cólera y el alza de la temperatura de superficie de las aguas que bañan las costas peruanas ${ }^{14}$. Por consiguiente, es presumible que la carga de enfermedad por las patologías descritas aumentará en la medida que el cambio climático se intensifique, afectando mayoritariamente a naciones en vías de desarrollo.

Una externalidad positiva del cambio climático es el favorecer el crecimiento de algunos cultivos mediado por el aumento de la concentración de $\mathrm{CO}_{2}$ atmosférico. Sin embargo, el escenario predictor más factible apunta hacia una disminución mundial de la oferta alimentaria, debido a la reducción de terrenos cultivables (secundaria al aumento del nivel oceánico costero, producto del derretimiento de grandes masas de hielo) y al aumento de sequías e inundaciones en diferentes regiones del planeta (secundarias a una mayor evaporación del agua y redistribución de las precipitaciones). En un mundo cuya población crece progresivamente, esta situación podría aumentar la 
tasa de desnutrición, -la cual afecta en la actualidad a 800 millones de personas ${ }^{15}$, siendo esta última un reconocido factor de riesgo para contraer enfermedades infecciosas ${ }^{4}$. Los escenarios predictores indican que los más afectados serán los pequeños agricultores, especialmente en aquellas regiones del planeta donde el suministro de alimentos ya es irregular ${ }^{1}$. El acceso a la tecnología en sectores y entornos claves determinará en grado considerable la capacidad de adaptación ante esta amenaza, constituyendo un desafío a enfren$\operatorname{tar}^{12}$.

Finalmente, el desplazamiento de refugiados ambientales debido a inundaciones y eventos climáticos extremos también ha sido asociado a un aumento de riesgo de transmisión de enfermedades vía agua y alimentos $^{2}$. En el año 2007, las lluvias e inundaciones ocurridas durante los monzones desplazaron cerca de 16 millones de habitantes en el sudeste asiático (11 millones en India, 4,5 millones en Bangladesh y 250 mil en Nepal) ${ }^{9}$. Generalmente, la infraestructura sanitaria del lugar que recibe a los migrantes se ve superada, asimismo, las instalaciones provisorias (e.g. albergues, campamentos) proveen un fecundo escenario para el surgimiento de brotes infecciosos y de contagio interpersonal producto del hacinamiento, acceso limitado a suministros de agua potable y alimentos, insuficiente oferta de atención médica, falta de higiene y deficientes barreras de contacto con animales y vectores ${ }^{16}$.

\section{Chile frente al cambio climático}

El Comité Asesor Nacional de Cambio Climático (entidad creada en 1996 y que actúa como institucionalidad nacional para abordar la temática en nuestro país), a través de la publicación Estrategia Nacional de Cambio Climático (CANCC) ${ }^{17}$, ha sostenido que Chile es un país social, económica y ambientalmente vulnerable al cambio climático. Por ello, gran parte de las consecuencias previstas por el Panel Intergubernamental de Expertos sobre Cambio Climático ${ }^{1}$ podrían ocurrir o ya están ocurriendo en el país. De igual forma, señala que Chile es parte ratificante de la Convención Marco de las Naciones Unidas sobre Cambio Climático y de su Protocolo de Kyoto ${ }^{18}$; como tal, tiene responsabilidad en el cumplimiento de las obligaciones adquiridas. Una parte fundamental de este documento tiene relación con los principales desafíos pendientes, cuales son: avanzar en estudios del impacto del cambio climático en determinados rubros; desarrollar estudios de mitigación de las emisiones de gases de efecto invernadero; e incorporar medidas de mitigación y adaptación en los planes de desarrollo nacional, regional y local. Es importante destacar que la participación del sector salud en el debate nacional en torno al tema no ha sido amplia. De hecho, de las nueve instituciones que componen el Comité Asesor Nacional de Cambio Climático (Comisiones Nacionales del Medio Ambiente-CONAMA, Energía y de Investigación Científica y Tecnológica-CONICYT; Ministerios de Relaciones Exteriores y Agricultura; Direcciones General de Territorio Marítimo y Marina Mercante y Meteorológica de Chile, Servicio Hidrográfico y Oceanográfico de la Armada de Chile y Academia Chilena de Ciencias), ninguna está vinculada directamente al sector salud.

\section{¿Qué podemos concluir a la luz de la evidencia expuesta?}

Si bien la evidencia disponible respalda la asociación entre cambio climático y emergencia/reemergencia de enfermedades infecciosas, este fenómeno es de tipo multifactorial, constituyendo una sobre-simplificación del mismo excluir otras variables en el modelo explicatorio final. Existe una serie de factores que juegan un rol clave, tales como la progresiva resistencia a insecticidas y medicamentos, deforestación, cambios en políticas públicas sanitarias (e.g. reducción de vigilancia, prevención y control vectorial), cambios demográficos (e.g. crecimiento poblacional, migraciones, urbanización) y cambios en las condiciones habitacionales (e.g. disponibilidad de redes de alcantarillado), entre otros, los cuales deben ser incluidos en el modelo explicatorio final ${ }^{5}$. Los escenarios predictores de temperaturas globales no son alentadores, existiendo numerosa evidencia que apunta hacia un aumento de las emisiones de gases con efecto invernadero durante las próximas décadas, incrementando el calentamiento global e induciendo cambios en el sistema climático planetario, cuya magnitud durante el siglo XXI excederá la observada durante el siglo $X^{1}$. Sin embargo, el panorama no es del todo sombrío. Existen diversas estrategias a implementar -tanto de adaptación como de mitigación-, íntimamente ligadas al desarrollo social y económico de los pueblos, cuya ejecución requiere de una amplia coordinación y cooperación internacional. Si bien las estrategias de mitigación y adaptación no pueden por sí solas evitar todos los efectos del cambio climático, éstas pueden complementarse para reducir significativamente los riesgos que este fenómeno planetario implica ${ }^{1}$. Es importante destacar el hecho de que, en el corto plazo, las estrategias de mitigación de emisiones de gases con efectos invernadero (e.g. reducción de quema de combustibles fósiles) pueden presentar numerosas externalidades positivas, principalmente secundarias a la reducción de los efectos adversos atribuibles a la contaminación ambiental. Entre estos efectos positivos destacan la reducción de hospitalizaciones por causa 
cardiovascular, consultas médicas infantiles, casos de crisis asmáticas y días de ausentismo laboral, entre $\operatorname{otros}^{19}$.

Siendo una de las principales consecuencias del cambio climático sus efectos sobre la salud humana, nuestra invitación como profesionales de la salud es a informarnos debidamente sobre el tema, con el fin último de participar activamente en el debate nacional e internacional en torno al mismo, hecho de vital importancia si se considera que las acciones que se emprendan hoy tendrán importantes efectos en la salud de generaciones venideras.

\section{Resumen}

Para la comunidad científica mundial, el aumento progresivo de la temperatura del clima planetario es un hecho inequívoco, proyectándose para el año 2100 un incremento de la temperatura promedio de $1,0{ }^{\circ} \mathrm{C}-3,5^{\circ} \mathrm{C}$. Las consecuencias pronosticadas son muy diversas, siendo en su mayoría adversas para la salud humana, entre las cuales se incluyen el establecimiento de escenarios epidemiológicos propicios para la emergencia y reemergencia de enfermedades infecciosas. El presente artículo sintetiza la evidencia disponible en torno a los mecanismos generadores del cambio climático, sus efectos medioambientales y sus consecuencias sobre la salud humana. Para ello, se describen cambios ya objetivados en la dinámica de enfermedades zoonóticas y vectoriales y de enfermedades transmitidas por agua y alimentos. Se comenta la posición de Chile en el concierto internacional y sus múltiples desafíos pendientes, destacándose la importancia de incorporar al debate nacional a profesionales que trabajan en el sector salud.

\section{Referencias}

1.- Intergovernmental Panel on Climate Change (IPCC). Fourth Assessment Report (AR4). Summary for Policymakers. Disponible en http://www.ipch.ch (Accedido el 17 junio 2008).

2.- Greer A, Ng V, Fisman D. Climate change and infectious diseases in North America; the road ahead. Can Med Assoc J 2008; 178: 715-22.

3.- Haines A, McMichael A, Epstein P. Environment and health: 2. global climate change and health. Can Med Assoc J 2000; 163: 729-34.

4.- Khasnis A, Nettleman M. Global warming and infectious disease. Arch Med Res 2005; 36: 689-96.

5.- Zell R. Global climate change and the emergence/re-emergence of infectious diseases. Int J Med Microbiol 2004; 293 (Suppl 37): 16-26.

6.- McMichael A, Woodruff R, Hales S. Climate change and human health: present and future risks. Lancet 2006; 367: 859-69.

7.- Shea K. Global climate change and children's health. Pediatrics 2007; 120: 1359-67.

8.- Barclay E. Is climate change affecting dengue in the Americas? Lancet 2008; 371: 973-4.

9.- Senior K. Climate change and infectious disease: a dangerous liaison? Lancet Infect Dis 2008; 8: 92-3.

10.- Rezza G, Nicoletti L, Angelini R, Romi R, Finarelli A C, Panning M. Infection with chikungunya virus in Italy: an outbreak in a temperate region. Lancet 2007; 370: $1840-6$.

11.- World Health Organization (WHO). Weekly Epidemiological Record 2008; 83: 105-8.

12.- World Health Organization (WHO). Climate change and human health-risks and responses. Summary. Disponible en http://www.who.int (Accedido el 17 junio 2008).

13.- Checkley W, Epstein L, Gilman R, Figueroa D, Cama R, Patz J, et al. Effects of El Niño and ambient temperature on hospital admissions for diarrhoeal diseases in Peruvian children. Lancet 2000; 355: 442-50.
14.- Gil A, Louis V, Rivera I, Lipp E, Huq A, Lanata C, Taylor D, et al. Occurrence and distribution of Vibrio cholerae in the coastal environment of Peru. Environ Microbiol 2004; 6: 699-706.

15.- Haddad L, Martorell R. Feeding the world in the coming decades requires improvements in investment, technology and institutions. J Nutr 2002; 132: 3435-6S.

16.- Wilson M E. Travel and the emergence of infectious diseases. Emerg Infect Dis 1995; 1: $39-46$

17.- Comité Nacional Asesor sobre Cambio Global. Estrategia Nacional de Cambio Climático 2006. Disponible en http://www.sinia.cl (Accedido el 13 abril 2008).

18.- United Nations (UN). Kyoto Protocol to the United Nations Framework Convention on Climate Change 1998. Disponible en http://unfccc.int/kyoto_protocol/items/ 2830.php (Accedido el 17 junio 2008).

19.- Cifuentes L, Borja-Aburto VH, Gouveia N, Thurston G, Davis D. Hidden health benefits of greenhouse gas mitigation. Science 2001; 293: 1257-9. 